\title{
História natural de Leptodactylus mystacinus e Leptodactylus fuscus (Anura: Leptodactylidae) no Cerrado do Brasil Central
}

\author{
Crizanto Brito De-Carvalho ${ }^{1}$, Evellyn Borges de Freitas ${ }^{1}$, Renato Gomes Faria ${ }^{1,5}$, \\ Renato de Carvalho Batista ${ }^{2}$, Cássio de Carvalho Batista ${ }^{2}$, \\ Welington Araújo Coelho ${ }^{3}$ \& Adriana Bocchiglieri ${ }^{4}$
}

${ }^{1}$ Departamento de Biologia, Universidade Federal de Sergipe - UFS, Cidade Universitária Prof. Aloísio de Campos, Jardim Rosa Elze, CEP 49100-000, São Cristóvão,SE, Brasil, e-mail: crizantobrito@gmail.com, evellynbf@yahoo.com.br,www.ufs.br ${ }^{2}$ Faculdades Integradas da Terra de Brasília - FTB,

Av. Recanto das Emas, Quadra 203, Lote 31, s/n, CEP 72610-300, Brasília, DF, Brasil, e-mail:renatobio18@yahoo.com.br,carvalhocb@yahoo.com.br,www.ftb.edu.br

${ }^{3}$ Campus I, Universidade Católica de Brasília - UCB,

Estrada Parque ConTorno - EPCT, Q.S. 07, Lote 01, Águas Claras,

CEP 71966-700, Brasília,DF, Brasil,e-mail:wtoncoelho@gmail.com,www.ucb.br

${ }^{4}$ Departamento de Ecologia, Universidade de Brasília - UnB, Campus Darcy Ribeiro, Asa Norte,

CEP 70919-970, Brasília, DF, Brasil, adriblue@unb.br,www.unb.br

${ }^{5}$ Autor para correspondência: Renato Gomes Faria, e-mail: renatogfaria@ufs.br

DE-CARVALHO, C.B., FREITAS, E. B., FARIA, R.G., BATISTA, R.C., BATISTA, C.C., COELHO, W.A. \& BOCCHIGLIERI, A. 2008. Natural history of Leptodactylus mystacinus and Leptodactylus fuscus (Anura: Leptodactylidae) in the Cerrado of Central Brazil. Biota Neotrop. 8(3): http://www.biotaneotropica.org.br/ v8n3/en/abstract?article+bn01308032008.

Abstract: Aspects of the ecology of Leptodactylus mystacinus and Leptodactylus fuscus were investigated in an area of the Cerrado of Central Brazil. The study included use of microhabitat, activity patterns, diet and, morphometry. Observations were conducted between April, 2006, and February, 2007. The species are sexually dimorphic females larger than males - and body size in L. mystacinus is larger than that of L. fuscus. Both species preferred the ground surface (microhabitat) of wetland habitats with herbaceous vegetation close to lentic water bodies. Leptodactylus mystacinus was observed most often in October and November (8:00-8:59 PM and 11:00-11:59 PM), and L. fuscus in November and October between 7:00 PM and 8:59 PM. The diet of both populations was based on Arthropoda, primarily Coleoptera, which was the most important order (IVI). Differences in the volumetric proportions of the categories of then preys used, and in the periods when they were most observed, are probably the factors that contribute the most to the coexistence of both species in the area. Intersexual differences in the diet were observed in both species. These differences were probably associated with the differential allocation of resources to the production of gametes or occasional differences in the use of space by the two sexes.

Keywords: ecology, diet, Leptodactylus.

DE-CARVALHO, C.B., FREITAS, E.B., FARIA, R.G., BATISTA, R.C., BATISTA, C.C., COELHO, W.A. \& BOCCHIGLIERI, A. 2008. História natural de Leptodactylus mystacinus e Leptodactylus fuscus (Anura: Leptodactylidae) no Cerrado do Brasil Central. Biota Neotrop. 8(3): http://www.biotaneotropica.org.br/v8n3/ pt/abstract?article+bn01308032008.

Resumo: Aspectos da ecologia de Leptodactylus mystacinus e Leptodactylus fuscus foram investigados em uma área de Cerrado do Brasil Central. O estudo incluiu o uso do microhábitat, padrões de atividade, dieta e morfometria. As observações foram conduzidas entre abril de 2006 a fevereiro de 2007 . As espécies são sexualmente dimórficas - fêmeas maiores que os machos - e o tamanho do corpo em L. mystacinus é maior do que o de L. fuscus. Ambas as espécies preferiram a superfície do solo (microhábitat) de hábitats brejosos com vegetação herbácea próximos a corpos lênticos de água. Leptodactylus mystacinus foi mais observado em Outubro e Novembro (20:00-20:59 e 23:00-23:59 horas) e L. fuscus em Novembro e Outubro das 19:00 às 20:59 horas. A dieta destas populações foi baseada em Arthropoda, primariamente Coleoptera, a qual foi a mais importante ordem (IVI). Diferenças nas proporções volumétricas das categorias de presas utilizadas, e nos períodos em que são mais observadas, provavelmente sejam os fatores que mais contribuem para a coexistência das duas espécies na área. Diferenças intersexuais na dieta foram observadas para estas espécies. Estas diferenças estão provavelmente associadas à alocação diferencial de recursos para a produção de gametas ou diferenças ocasionais no uso do espaço pelos dois sexos.

Palavras-chave: ecologia, dieta, Leptodactylus. 


\section{Introdução}

O estudo de uma comunidade completa é relativamente difícil e demanda uma quantidade grande de especialistas. Devido a essas dificuldades, a maior parte dos estudos envolve agrupamentos menores como taxocenoses ou mesmo pares, trios ou outras formações de espécies, em geral, filogeneticamente próximas (e.g. Eterovick \& Sazima 2000, Bertoluci \& Rodrigues 2002a, Santos et al. 2004, Brasileiro et al. 2005, Haddad \& Prado 2005, Menin et al. 2005). Diferenças na morfologia, nas estratégias de forrageamento e na utilização do hábitat por espécies simpátricas podem reduzir os efeitos negativos que uma espécie teria sobre a outra, facilitando assim a sua coexistência (Pianka 1973, Schoener 1977).

A partilha do espaço nos anfíbios, por exemplo, inclui a exploração de uma grande diversidade de microambientes, como sítios reprodutivos (oviposição e desenvolvimento larval) ou de forrageamento, os quais podem ser utilizados de modos distintos por várias espécies (Duellman \& Trueb 1994, Stebbins \& Cohen 1997, Bertoluci \& Rodrigues 2002a). Muitos anuros são insetívoros e considerados forrageadores oportunistas, sendo suas dietas um reflexo da disponibilidade de presas no ambiente (Eterovick \& Sazima 2004). Táticas de forrageamento podem variar entre os anuros, indo desde forrageadores que caçam por espreita até aqueles que buscam ativamente por presas (Duellman \& Trueb 1994). Esses comportamentos, associados à ocupação diferencial do ambiente, acabam influenciando nos tipos de presas ingeridas (Van Sluys \& Rocha 1998).

A temporada reprodutiva em anuros está normalmente relacionada a fatores como pluviosidade, temperatura, umidade relativa e à disponibilidade de ambientes aquáticos temporários (Bernarde \& Anjos 1999, Ávila \& Ferreira 2004, Thomé \& Brasileiro 2007). Com relação à duração dos eventos reprodutivos, os anuros podem ser classificados como de reprodução explosiva, aqueles cujos eventos reprodutivos ocorrem por apenas alguns dias; ou de reprodução prolongada, cuja duração excede o período anteriormente relatado (Wells 1977). Atualmente são reconhecidos 39 modos reprodutivos em anfíbios (Haddad \& Prado 2005), definidos por um conjunto de características como o lugar onde são depositados os ovos, características da ninhada, duração do desenvolvimento, estágio e forma de alimentação dos girinos e presença ou não de cuidado parental (Duellman \& Trueb 1994, Machado 2003, Eterovick \& Sazima 2004, Haddad \& Prado 2005, Santos \& Amorim 2006).

A família Leptodactylidae é representada por quatro gêneros (Hydrolaetare, Scythrophrys, Paratelmatobius e Leptodactylus) e 95 espécies (Frost 2008). A maior parte dessas está contida no gênero Leptodactylus (85 espécies), sendo representados em geral por animais de pequeno e médio porte, insetívoros, terrestres ou semiaquáticos, e de atividade noturna (Frost 2008). Esses animais vivem associados à serapilheira de florestas tropicais úmidas, ou próximos à água, com exceção de algumas espécies que habitam ambientes áridos e cujos modos reprodutivos são bastante variados (Duellman \& Trueb 1994, Pough et al. 2004). Algumas espécies do gênero Leptodactylus (e.g. Leptodactylus furnarius e L. jolyi) constroem ninhos de espuma no interior de tocas subterrâneas, importantes para evitar a dessecação dos ovos e garantir a proteção das larvas em desenvolvimento contra predadores, particularmente em ambientes onde a distribuição das chuvas é irregular ao longo da estação reprodutiva (Heyer 1969).

Leptodactylus mystacinus (Burmeister 1861) é encontrado em hábitats mésicos subtropicais áridos das encostas dos Andes na Bolívia e Yungas, noroeste da Argentina, estendendo-se do leste através do Mato Grosso e Goiás até a Bahia, no Brasil. Esta espécie ocorre no Chaco e grande parte do domínio morfoclimático do Cerrado, principalmente em ambientes abertos (Heyer et al. 2003). Já Leptodactylus fuscus (Schneider, 1799) está distribuído na maior parte da América do Sul situada a leste dos Andes e Panamá (Heyer 1978).

Espécies com portes semelhantes podem coexistir quando exploram hábitats diferentes, apresentam períodos de atividades distintos e/ou divergem no tipo de presas utilizadas (Schoener 1794). Leptodactylus mystacinus e L. fuscus já foram observados em simpatria em outras localidades do Brasil como em Botucatu, SP por Rossa-Feres \& Jim (1996), Rio Claro, SP por Toledo et al. (2003) e Zina et al. (2007) e em Itirapina e Brotas, SP por Oyamaguchi (2006). Semelhanças no uso de microhábitats (Ávila \& Ferreira 2004, Borges \& Juliano 2007) e período de atividade (meses do ano e parte dos horários de atividade) (Ávila \& Ferreira 2004) já foram também registradas para essas duas espécies em situações de simpatria.

Baseado no tamanho semelhante e ampla distribuição geográfica de L. mystacinus e L. fuscus, bem como a utilização de recursos similares verificados em outras localidades, foram investigados os possíveis mecanismos que permitem a coexistência dessas duas espécies em uma área de Cerrado do Brasil Central. O presente trabalho teve por objetivo avaliar como Leptodactylus mystacinus e Leptodactylus fuscus da Fazenda Porta do Céu, Novo Gama - GO utilizam os recursos espaciais, tróficos e temporais.

\section{Material e Métodos}

As populações de Leptodactylus mystacinus e Leptodactylus fuscus foram estudadas em uma área de Cerrado pertencente à Fazenda Porta do Céu (16 $16^{\circ}$ ' 50" S e 48 04' 49” W), município do Novo Gama - GO, situado a 70 km de Brasília. Com uma área de 582,3 ha, a fazenda mantém fitofisionomias típicas do Cerrado como matas de galeria, cerrado sentido restrito e campos que estão em bom estado de conservação. O clima é sazonal com duas estações bem definidas, um inverno seco (abril a setembro) e um verão chuvoso (outubro a março) (Eiten 1972). A precipitação média anual fica entre 1.500 a $1.700 \mathrm{~mm}$ (Nimer 1989).

Os dados foram tomados por dois observadores, sendo adotadas duas noites consecutivas a cada semana entre os meses de abril de 2006 a fevereiro de 2007. Foram realizadas buscas ativas aos animais entre as 18:00 e 03:00 horas em duas áreas de brejo, três lagoas, um fragmento de mata de galeria e duas poças temporárias. Encontros ocasionais nas proximidades de edificações humanas foram também considerados. Na primeira noite de cada semana foram vistoriadas as áreas de brejo e lagoas e na segunda um transecto de aproximadamente quatro quilômetros passando por uma área aberta (campo limpo), mata de galeria e um cerrado denso. Na segunda noite as poças temporárias foram também vistoriadas.

No momento da captura foram tomadas informações referentes ao ambiente amostrado, horário, se o animal estava em atividade (vocalizando), substrato utilizado e estrato predominante da vegetação (herbáceo, arbóreo, arbustivo). Os animais coletados foram acondicionados separadamente em sacos plásticos, cada um contendo uma etiqueta de identificação. Dados ambientais, como temperatura (mínima, média e máxima), precipitação e umidade tomados na estação meteorológica mais próxima da área de estudo (Distrito Federal) foram cedidos pelo INPE (2007) e utilizados para avaliar se existe relação entre as variáveis ambientais e as freqüências relativas dos animais.

Depois de coletados, os Leptodactylus foram sacrificados com injeção de lidocaína $2 \%$. A massa foi mensurada com o auxílio de um dinamômetro do tipo Pesola ${ }^{\circledR}$ (precisão de 0,5 g) e 21 medidas foram tomadas com um paquímetro digital Digimess ${ }^{\circledR}$ (precisão de $0,01 \mathrm{~mm}$ ): CRC (comprimento rostro-cloacal); largura e altura do corpo; comprimento, largura e altura da cabeça; diâmetro do tímpano e do olho; distância inter-ocular, olho-narina e inter-nasal; compri- 
mento e largura do braço, antebraço, coxa e perna e comprimento da mão e do pé. Todas as medidas de estruturas pares foram tomadas do lado direito do corpo do animal.

Depois de medidos, os animais foram devidamente etiquetados, fixados em formalina 10\% e conservados em álcool 70\%. A condição reprodutiva $(\mathrm{CR})$ dos animais foi verificada analisando as gônadas (fêmeas) e o saco vocal (machos), sendo atribuídas para cada sexo duas classes: reprodutivo ou não reprodutivo. As fêmeas reprodutivas eram aquelas cujos ovidutos estavam bastante enovelados e os ovários bem desenvolvidos e os machos considerados reprodutivos eram aqueles que apresentavam saco vocal bastante evidente.

Em laboratório, os estômagos foram retirados e abertos e os seus conteúdos triados em lupa. Os itens encontrados foram identificados normalmente em nível de ordem e algumas vezes família. As presas foram contadas e aquelas encontradas inteiras medidas com paquímetro quanto ao maior comprimento e largura e seus volumes estimados através da fórmula do volume do elipsóide (ver Magnusson et al. 2003)

$$
\text { Volume }=\left(\varpi \text {.comprimento. } \text { largura }^{2}\right) / 6
$$

Para investigar possíveis diferenças na dieta foram calculadas as larguras de nicho alimentar (B) para as espécies (machos e fêmeas agrupados) e para cada sexo separadamente utilizando o índice de diversidade de Simpson (1949), onde B varia de um (uso exclusivo de uma categoria de presa) a n (uso homogêneo de todas as categorias). As sobreposições de nicho alimentar $(\phi)$ entre espécies e entre machos e fêmeas de cada espécie foram calculadas pelo índice de sobreposição simétrica (Pianka 1973). Valores próximos a zero indicam não haver similaridade nas dietas, ao passo que valores próximos a um indicam dietas similares.

As freqüências numéricas e volumétricas dos itens alimentares foram também comparadas através do teste de KolmogorovSmirnov. Um índice de valor de importância (IVI) foi calculado para verificar com quanto cada item alimentar participa na dieta dos Leptodactylus, através da seguinte equação (ver Gadsden \& Palacios-Orona 1997):

$\mathrm{IVI}=\mathrm{N} \%+\mathrm{V} \% / 2$

na qual $\mathrm{N}$ é o número e $\mathrm{V}$ o volume das presas utilizadas, todos em porcentagem.

Uma correlação canônica entre dois grupos de variáveis (comprimento máximo e largura máxima das presas versus comprimento, largura e altura da cabeça dos indivíduos analisados) foi realizada para investigar as relações entre as dimensões das presas e as medidas da cabeça dos anuros.

Todas as medidas morfométricas e as dimensões das presas obtidas dos estômagos dos animais coletados foram $\log _{10}$ - transformados para aproximar a amostra de uma distribuição normal e reduzir os efeitos de escala. O tamanho do corpo (CRC) foi comparado entre as espécies e os sexos por uma análise de variância (ANOVA) para dois fatores (espécie e sexo). Quanto às demais variáveis, foram feitas regressões lineares simples entre o CRC e as mesmas, sendo salvo os resíduos, para que se reduzisse o efeito de tamanho (CRC) sobre essas variáveis. Realizou-se então uma análise de componentes principais (ACP) das variáveis morfológicas tamanho-ajustadas (resíduos anteriormente relatados) para examinar possíveis diferenças na morfologia entre as espécies. As massas foram comparadas por uma ANOVA para dois fatores (sexo e espécie) dos resíduos das regressões tamanho (CRC) versus $\log _{10}$-massa.

Diferenças interespecíficas na utilização do hábitat, horários de coleta e meses de encontro foram testadas usando KolmogorovSmirnov e as variações relacionadas ao tipo de ambiente, estrato predominante da vegetação e microhábitats (substratos) ocupados por cada espécie por qui-quadrado. Larguras de nicho e sobreposições em relação aos parâmetros espaciais e temporais foram calculadas usando as mesmas fórmulas relatadas para a dieta.

Para as análises estatísticas os dados foram armazenados em planilhas do Excel 2003 e as análises realizadas nos softwares Systat 11.0 e BioEstat 4.0, todos para Windows. O nível de significância adotado para os testes de hipótese foi de 5\%. Todos os animais coletados foram depositados na coleção Herpetológica da UNB (CHUNB).

\section{Resultados}

Foram verificadas diferenças no tamanho (CRC) entre as espécies de Leptodactylus (ANOVA, $\mathrm{F}_{1,50}=85,353 ; \mathrm{P}<0,001 ; \mathrm{N}=54$; Tabela 1) e entre os sexos (ANOVA, $\mathrm{F}_{1,50}=10,681 ; \mathrm{P}=0,002 ; \mathrm{N}=54$; Tabela 1), porém o mesmo não foi observado para a interação espéciesexo (ANOVA, $F_{1,50}=0,608 ; P=0,439 ; N=54 ;$ Tabela 1). Diferenças significativas nas massas ajustadas foram também encontradas entre as espécies (ANOVA, $\mathrm{F}_{1,50}=53,775 ; \mathrm{P}<0,001 ; \mathrm{N}=54$; Tabela 1 ) e os sexos (ANOVA, $\mathrm{F}_{1,50}=11,606 ; \mathrm{P}=0,01 ; \mathrm{N}=54$; Tabela 1 ), o mesmo não ocorrendo para a interação espécie-sexo (ANOVA, $\mathrm{F}_{1,50}=0,199$; $\mathrm{P}=0,657 ; \mathrm{N}=54$; Tabela 1 ). Apesar das diferenças verificadas em tamanho, as duas espécies possuem formas semelhantes evidenciadas pelos resultados da análise de componentes principais (ACP) dos dados morfológicos tamanho-ajustados (Figura 1, Tabela 2). Porém, os dois primeiros componentes acumularam menos de $35 \%$ da variância explicada pelo conjunto dos componentes da ACP.

Um resumo das variáveis climáticas (temperaturas média, mínima e máxima, precipitação e umidade) para o período de execução do trabalho e das freqüências relativas das espécies encontra-se na Figura 2. Não foram verificadas diferenças com relação à época em que as duas espécies são mais observadas ao longo do ano (Kolmogorov-Smirnov, $\mathrm{D}_{\max }=0,090$, g.1. $=2 ; \mathrm{P}=0,4449 ;$ larguras de nicho L. mystacinus $-\mathrm{B}_{\text {mystacinus }}=3,13$ e L. fuscus $-\mathrm{B}_{\text {fuscus }}=2,39$; sobreposição $\left.\phi_{\mathrm{jk}}=0,95\right)$.

As duas espécies diferiram com relação aos horários de coleta (Kolmogorov-Smirnov, $\mathrm{D}_{\max }=0,2500$, g.l. $=2 ; \mathrm{P}=0,0019$; $\mathrm{B}_{\text {mystacinus }}=5,17$ e $\mathrm{B}_{\text {fuscus }}=4,25 ; \phi_{\mathrm{jk}}=0,82$ ). Leptodactylus mystacinus foi encontrado entre as 18:00 e 3:00 horas, com picos entre 20:00 e

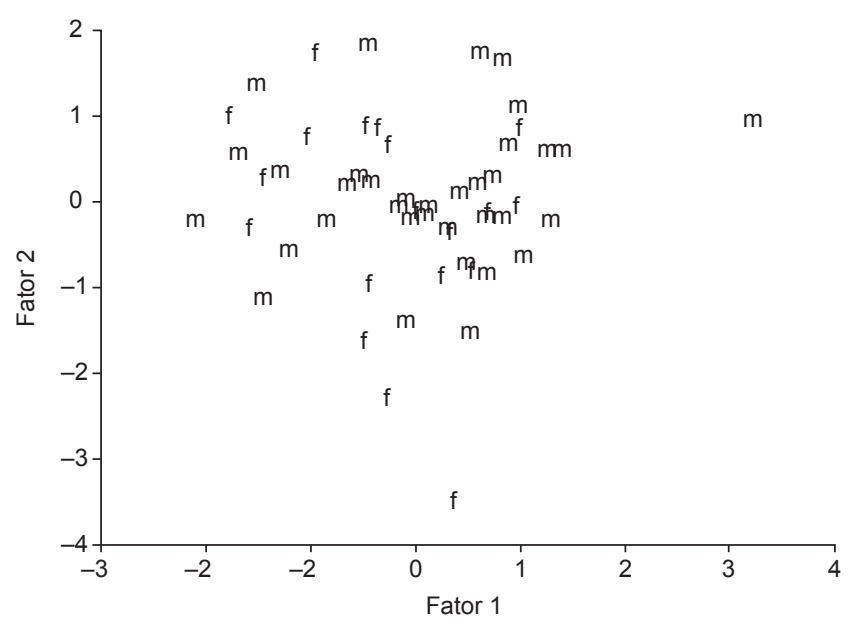

Figura 1. Escores dos fatores para componente principal I e componente principal II das variáveis morfológicas tamanho-ajustadas para L. mystacinus (m) e L. fuscus (f) do Novo Gama, Goiás, Brasil.

Figure 1. Factor scores for PC I and PC II of the size-adjusted morphological variables for L. mystacinus (m) and L. fuscus (f) from Porta do Céu farm, Novo Gama, Goiás, Brazil. 
De-Carvalho, C.B. et al.

Tabela 1. Medidas morfométricas de machos e fêmeas de L. mystacinus e L. fuscus do Novo Gama, GO, Brasil.

Table 1. Morphometric measurements of male and female L. mystacinus and L. fuscus from Novo Gama, GO, Brazil.

\begin{tabular}{|c|c|c|c|c|c|c|c|c|}
\hline \multirow{3}{*}{$\begin{array}{c}\text { Medidas } \\
\text { morfométricas }\end{array}$} & \multicolumn{4}{|c|}{ Leptodactylus mystacinus $(\mathbf{N}=35)$} & \multicolumn{4}{|c|}{ Leptodactylus fuscus $(\mathrm{N}=19)$} \\
\hline & \multicolumn{2}{|c|}{$\operatorname{Machos}(\mathbf{N}=17)$} & \multicolumn{2}{|c|}{ Fêmeas $(\mathrm{N}=18)$} & \multicolumn{2}{|c|}{$\operatorname{Machos}(\mathbf{N}=13)$} & \multicolumn{2}{|c|}{ Fêmeas $(\mathrm{N}=6)$} \\
\hline & $\overline{\mathbf{x}} \pm \mathbf{d p}$ & Min-Max & $\overline{\mathbf{x}} \pm \mathbf{d p}$ & Min-Max & $\overline{\mathbf{x}} \pm \mathbf{d p}$ & Min-Max & $\overline{\mathbf{x}} \pm \mathbf{d p}$ & Min-Max \\
\hline Massa & $16,2 \pm 2,6$ & $10,0-22,8$ & $19,7 \pm 4,5$ & $9,0-25,0$ & $10,0 \pm 1,2$ & $8,5-13,0$ & $12,8 \pm 2,4$ & $9,0-15,0$ \\
\hline Comprimento Rostro-Cloacal & $55,8 \pm 2,2$ & $50,5-58,4$ & $60,8 \pm 5,5$ & $46,9-69,9$ & $46,9 \pm 2,7$ & $42,6-51,0$ & $49,3 \pm 2,6$ & $45,4-52,6$ \\
\hline Largura do corpo & $24,2 \pm 3,9$ & $10,7-27,6$ & $30,0 \pm 2,9$ & $21,6-34,1$ & $15,9 \pm 3,3$ & $11,3-21,7$ & $18,0 \pm 5,1$ & $10,7-23,5$ \\
\hline Altura do corpo & $13,4 \pm 2,0$ & $10,9-18,4$ & $14,8 \pm 2,2$ & $10,3-18,8$ & $12,3 \pm 0,9$ & $10,9-13,7$ & $11,8 \pm 2,3$ & $7,9-14,3$ \\
\hline Comprimento da cabeça & $21,2 \pm 2,8$ & $17,5-25,7$ & $21,4 \pm 2,1$ & $17,9-25,3$ & $17,3 \pm 1,4$ & $14,9-19,7$ & $17,7 \pm 1,5$ & $15,1-19,2$ \\
\hline Largura da cabeça & $18,4 \pm 1,8$ & $14,4-21,8$ & $19,6 \pm 1,7$ & $15,4-23,0$ & $15,1 \pm 1,3$ & $12,9-17,3$ & $14,9 \pm 1,7$ & $12,2-17,3$ \\
\hline Altura da cabeça & $9,6 \pm 1,0$ & $7,7-11,5$ & $10,8 \pm 0,9$ & $8,7-12,2$ & $7,3 \pm 1,4$ & $4,3-9,8$ & $5,9 \pm 1,8$ & $2,9-8,1$ \\
\hline Diâmetro do tímpano & $4,3 \pm 0,5$ & $3,6-5,3$ & $4,7 \pm 0,7$ & $2,7-6,4$ & $3,4 \pm 0,3$ & $2,9-4,1$ & $3,5 \pm 0,4$ & $3,1-4,3$ \\
\hline Distância interocular & $8,0 \pm 1,1$ & $4,4-9,3$ & $8,6 \pm 0,9$ & $6,6-10,5$ & $6,4 \pm 0,5$ & $5,4-7,3$ & $6,6 \pm 0,5$ & $6,1-7,4$ \\
\hline Distância olho-narina & $5,1 \pm 0,6$ & $3,3-6,4$ & $6,0 \pm 0,6$ & $4,2-7,2$ & $4,3 \pm 0,4$ & $3,7-5,2$ & $5,0 \pm 0,1$ & $4,7-5,1$ \\
\hline Diâmetro do olho & $5,3 \pm 0,7$ & $3,9-6,6$ & $5,3 \pm 0,8$ & $2,9-6,8$ & $4,3 \pm 0,6$ & $3,6-5,3$ & $5,0 \pm 0,4$ & $4,5-5,5$ \\
\hline Distância internasal & $4,1 \pm 0,5$ & $3,0-5,5$ & $4,4 \pm 0,7$ & $2,2-5,7$ & $3,2 \pm 0,6$ & $2,3-4,2$ & $3,2 \pm 0,6$ & $2,4-4,0$ \\
\hline Comprimento do braço & $9,5 \pm 1,9$ & $6,0-12,9$ & $9,5 \pm 2,0$ & $5,5-12,0$ & $6,2 \pm 1,7$ & $3,9-8,9$ & $6,9 \pm 2,2$ & $4,7-9,0$ \\
\hline Largura do braço & $4,3 \pm 0,6$ & $3,4-5,9$ & $4,3 \pm 0,7$ & $2,7-5,7$ & $4,0 \pm 0,5$ & $3,3-4,8$ & $3,5 \pm 0,4$ & $3,1-4,1$ \\
\hline Comprimento do antebraço & $9,8 \pm 1,3$ & $8,0-12,8$ & $10,5 \pm 1,5$ & $6,4-13,2$ & $7,3 \pm 1,2$ & $5,5-9,8$ & $7,3 \pm 0,6$ & $6,6-8,0$ \\
\hline Largura do antebraço & $4,9 \pm 0,8$ & $2,7-6,3$ & $4,9 \pm 1,1$ & $2,4-6,7$ & $4,1 \pm 0,7$ & $2,9-5,3$ & $3,9 \pm 0,4$ & $3,3-4,7$ \\
\hline Comprimento da mão & $12,1 \pm 1,5$ & $8,8-14,4$ & $13,3 \pm 2,4$ & $9,3-20,2$ & $9,3 \pm 1,3$ & $7,3-11,7$ & $9,2 \pm 1,4$ & $7,2-11,3$ \\
\hline Comprimento da coxa & $20,0 \pm 2,6$ & $14,3-22,6$ & $19,5 \pm 3,1$ & $13,9-25,0$ & $18,5 \pm 2,2$ & $15,3-22,0$ & $20,2 \pm 2,5$ & $16,5-22,7$ \\
\hline Largura da coxa & $11,0 \pm 1,4$ & $8,9-13,4$ & $11,6 \pm 1,4$ & $9,0-13,6$ & $8,7 \pm 1,1$ & $6,6-10,5$ & $8,9 \pm 1,4$ & $7,2-10,5$ \\
\hline Comprimento da perna & $22,8 \pm 4,1$ & $19,2-36,4$ & $24,9 \pm 3,0$ & $17,8-29,5$ & $22,6 \pm 3,0$ & $19,1-29,3$ & $24,1 \pm 3,5$ & $18,8-28,4$ \\
\hline Largura da perna & $9,2 \pm 0,8$ & $7,3-10,1$ & $9,7 \pm 1,3$ & $6,8-11,6$ & $7,5 \pm 0,7$ & $6,0-8,7$ & $7,9 \pm 1,2$ & $6,0-9,3$ \\
\hline Comprimento do pé & $33,7 \pm 3,5$ & $25,3-36,9$ & $37,2 \pm 2,8$ & $28,6-42,4$ & $35,5 \pm 1,7$ & $32,7-38,4$ & $38,2 \pm 2,5$ & $35,3-41,4$ \\
\hline
\end{tabular}

20:59 e 23:00 e 23:59 horas (Figura 3) e L. fuscus entre 18:00 e 00:59 horas e pico entre 19:00 e 20:59 horas, não sendo observado nenhum animal em amplexo (Figura 3). Dos 17 machos de L. mystacinus coletados, apenas quatro $(23,52 \%)$ estavam vocalizando (três deles entre 19:30 e 22:30 e um as 02:50 horas) e dos 13 L. fuscus, sete vocalizavam $(53,84 \%)$ (seis entre 18:30 e 20:40 e um as 23:50 horas). Leptodactylus mystacinus foi observado vocalizando em agosto (1 indivíduo), novembro (2) e dezembro (1); já L. fuscus em outubro (3) e novembro (4).

As duas espécies ocuparam hábitats semelhantes (KolmogorovSmirnov, $\mathrm{D}_{\max }=0,1188$, g.l. $=1 ; \mathrm{P}=0,6367 ; \mathrm{B}_{\text {mystacinus }}=1,35 \mathrm{e}$ $\left.\mathrm{B}_{\text {fuscus }}=1,38 ; \phi_{\mathrm{jk}}=0,99\right)$, sendo as áreas de brejo as mais utilizadas (Figura 4). Não foi verificada variação com relação ao tipo de ambiente $\left(\chi^{2}=3,046 ;\right.$ g.l. $=1 ; \mathrm{P}=0,2446 ; \mathrm{B}_{\text {mystacinus }}=1,06$ e $\left.\mathrm{B}_{\text {fuscus }}=1,00\right) \mathrm{e}$ estrato predominante da vegetação $\left(\chi^{2}=3,046 ;\right.$ g.l. $=1 ; \mathrm{P}=0,081$; $\mathrm{B}_{\text {mystacinus }}=1,06$ e $\left.\mathrm{B}_{\text {fuscus }}=1,00 ; \phi_{\mathrm{jk}}=1,00\right)$, com as espécies tendo preferência por locais abertos (L. mystacinus $-97 \%$ e L. fuscus $100 \%$ das observações) e com predomínio de herbáceas (L. mystacinus - 97\% e L. fuscus $100 \%$ das observações). Uma alta sobreposição no uso dos substratos $\left(\phi_{\mathrm{jk}}=1,00 ; \chi^{2}=1,724 ;\right.$ g.l. $=1 ; \mathrm{P}=0,4895$; $\mathrm{B}_{\text {mystacinus }}=1,19$ e $\left.\mathrm{B}_{\text {fuscus }}=1,00\right)$ foi verificada, com a superfície do solo sendo a principal categoria utilizada pelas duas espécies (L. mystacinus $91 \%$ e L. fuscus $100 \%$ ), sendo que L. mystacinus foi observado também sobre a serapilheira (9\%).

Foram analisados 35 estômagos de L. mystacinus (17 machos e 18 fêmeas) e 19 de L. fuscus (13 machos e 6 fêmeas). Leptodactylus mystacinus consumiu 38 itens distribuídos em nove categorias de presas e L. fuscus 51 itens divididos em oito categorias (Tabela 3). Os itens mais frequientes para L. mystacinus foram material vegetal (34\%), Isoptera e larvas de insetos (11\% cada) e para L. fuscus Coleoptera e Isoptera (ambos 19\%) e larvas de insetos (16\%) (Tabela 3). Não foram verificadas diferenças com relação às proporções numéricas em que os itens alimentares foram utilizados pelas duas espécies (Kolmogorov-Smirnov, $\mathrm{D}_{\max }=0,1485 ; \mathrm{g} .1=2$; $\mathrm{p}=0,1078 ; \phi_{\mathrm{jk}}=0,87 ;$ Tabela 3$)$. Leptodactylus mystacinus consumiu principalmente Hymenoptera $(26 \%)$ e larvas de insetos (16\%) e L. fuscus Isoptera (29\%) e Hymenoptera (24\%; Tabela 4). Já as proporções volumétricas diferiram entre L. mystacinus e L. fuscus (Kolmogorov-Smirnov, $\mathrm{D}_{\text {max }}=0,1931 ;$ g.l. $=2 ; \mathrm{p}=0,0223$; $\phi_{\mathrm{jk}}=0,87 ;$ ), com a primeira espécie ingerindo principalmente Coleoptera (41\%) e larvas de insetos $(29 \%)$ e a segunda Coleoptera (47\%), larva de insetos (19\%) e Isoptera (17\%) (Tabela 3). Os itens mais importantes (IVI) para ambas as espécies foram Coleoptera (L. mystacinus 27,00 e L. fuscus 33,50, seguidos por larva de lepidoptera para L. mystacinus $(22,50)$ e Isoptera para L. fuscus $(23,00)$ (Tabela 3).

Com relação a L. mystacinus, os machos predaram sete categorias de presas e as fêmeas nove (Tabela 4). As categorias mais frequientes para machos foram material vegetal $(48,0 \%)$ e Diptera $(14,0 \%)$ e para as fêmeas, material vegetal (24\%), Isoptera e Orthoptera (14\% cada um) (Tabela 4). Foram verificadas diferenças com relação às proporções numéricas em que os itens alimentares foram utiliza- 


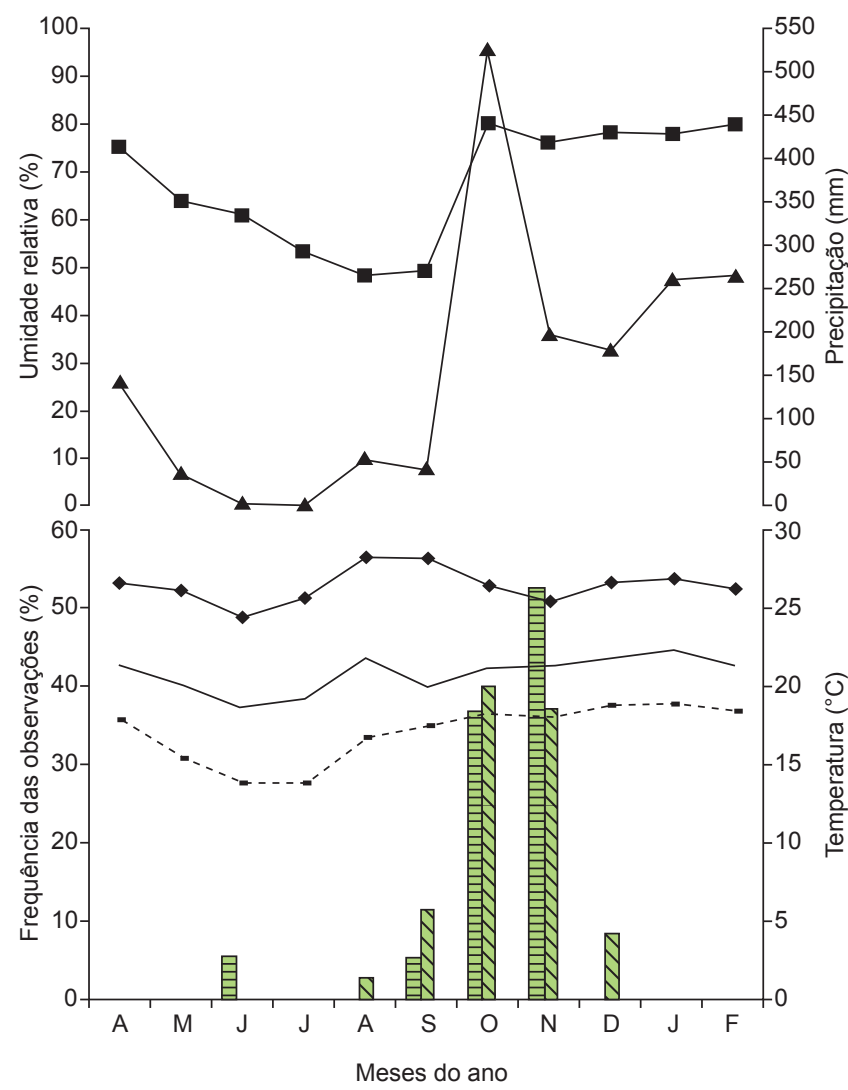

Figura 2. Valores mensais das variáveis climáticas, tomadas na estação meteorológica mais próxima (Brasília) do sítio de estudo no Novo Gama, entre abril 2006 a fevereiro de 2007: precipitação (- $\mathbf{\Delta}$-); umidade relativa do ar (-匹-); temperaturas mínima (--), média (-) e máxima (- - -). Barras com linhas horizontais representam as frequiências relativas mensais de $L$. fuscus e as barras com linhas diagonais de L. mystacinus.

Figure 2. Monthly values for climatic variables, obtained from the nearest meteorological station (Brasília) to the study site in Novo Gama between April, 2006, and February, 2007: precipitation (- $\mathbf{\Delta}-)$; relative humidity $(-\boldsymbol{-}-)$;minimum (--), mean (-) and maximum (- $\downarrow-)$ temperatures. Bars with horizontal stripes represent the relative monthly frequencies of $L$. fuscus and bars with diagonal stripes those of L. mystacinus.

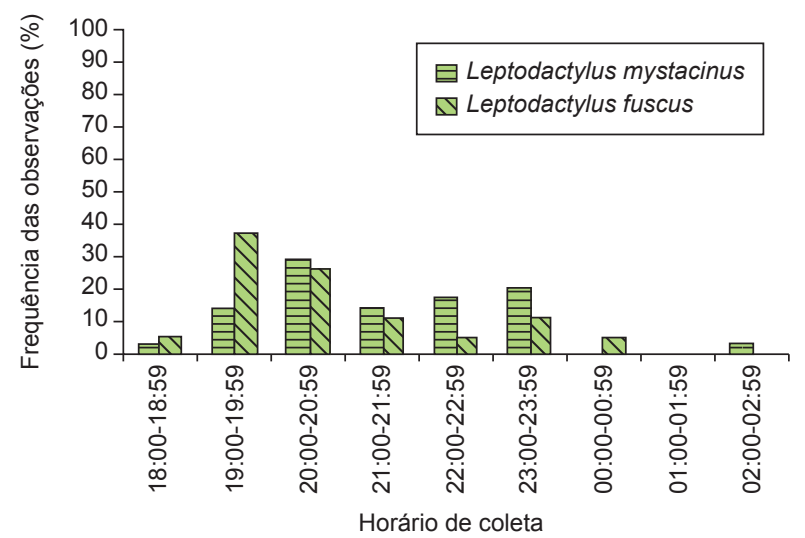

Figura 3. Frequiência relativa dos horários de atividade de L. mystacinus e L. fuscus, do Novo Gama.

Figure 3. Relative frequency of activity period in L. mystacinus and L. fuscus from Novo Gama.

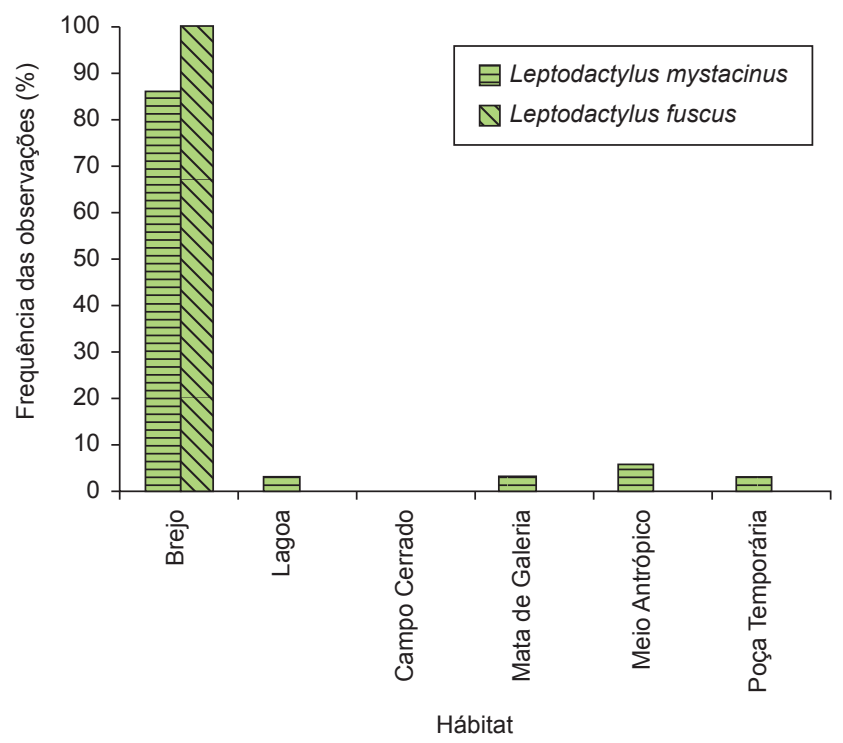

Figura 4. Freqüência relativa de uso de diferentes hábitats por L. mystacinus e L. fuscus do Novo Gama.

Figure 4. Relative frequency of the different habitats used by L. mystacinus and L. fuscus from Novo Gama.

dos por cada um dos sexos (Kolmogorov-Smirnov, $\mathrm{D}_{\max }=0,3898$, g.l. $=2 ; \mathrm{P}<0,0001 ; \phi_{\mathrm{jk}}=0,47$; Tabela 4). Os machos predaram principalmente Coleoptera, Diptera e larvas de insetos (25\% cada) e as fêmeas Hymenoptera (35\%) e Isoptera (19\%) (Tabela 4). As proporções volumétricas foram também distintas entre machos e fêmeas (Kolmogorov-Smirnov, $\mathrm{D}_{\max }=0,4431$, g.l. = 2; P < 0,0001; $\left.\phi_{\mathrm{jk}}=0,51\right)$. Machos ingerem principalmente larvas de insetos (41\%) e Diptera (34\%) e as fêmeas Coleoptera (56\%) e larvas de inseto (23\%) (Tabela 4). Os itens mais importantes (IVI) para machos foram larvas de insetos $(33,0)$ e Diptera $(29,5 \%)$ e para as fêmeas Coleoptera $(32,0)$ e Hymenoptera $(24,5 \%)$ (Tabela 4).

Para Leptodactylus fuscus, os machos predaram nove categorias de presas e as fêmeas seis (Tabela 4). Os itens mais freqüentes para machos foram Coleoptera, larvas de insetos (20\% cada) e Isoptera (15\%), já para as fêmeas Isoptera (27\%), Coleoptera, Hymenoptera e Orthoptera (cada um com 18\%) (Tabela 4). Foram verificadas diferenças com relação às proporções numéricas em que os itens alimentares foram utilizados pelos sexos (Kolmogorov-Smirnov, $\mathrm{D}_{\max }=0,3898$, g.l. $=2 ; \mathrm{P}<0,0001 ; \phi_{\mathrm{jk}}=0,75$ ) (Tabela 4). Os machos predaram principalmente larvas de insetos (25\%), Coleoptera e Hymenoptera (ambos 20\%) e as fêmeas Isoptera (39\%) e Hymenoptera (26\%) (Tabela 4). As proporções volumétricas também diferiram entre machos e fêmeas (Kolmogorov-Smirnov, $\mathrm{D}_{\max }=0,4431$, g.l. $=2$; $\left.\mathrm{P}<0,0001 ; \phi_{\mathrm{jk}}=0,14\right)$. Machos ingerem principalmente larvas de insetos (78\%) e Coleoptera (8\%) e as fêmeas Coleoptera (58\%) e Isoptera (20\%) (Tabela 4). Os itens mais importantes (IVI) para os machos foram larvas de insetos $(51,5 \%)$ e para as fêmeas Coleoptera $(38,5 \%)$ e Isoptera $(29,5 \%)$ (Tabela 4). Não foram verificadas relações entre as dimensões das presas e as medidas da cabeça de L. mystacinus e L. fuscus (Tabela 5).

Dos 35 indivíduos coletados de Leptodactylus mystacinus (17 machos e 18 fêmeas), nove (6 fêmeas e 3 machos) estavam reprodutivos. O comprimento rostro-cloacal (CRC) de Leptodactylus mystacinus variou de 50,8 a $58,4 \mathrm{~mm}$ para machos, com o menor indivíduo reprodutivo com $56,53 \mathrm{~mm}$ e para as fêmeas de 46,9 a $70,0 \mathrm{~mm}$, com a menor fêmea reprodutiva com $69,99 \mathrm{~mm}$. Dos 
Tabela 2. Escores dos cinco primeiros componentes principais das variáveis morfométricas tamanho-ajustadas de L. mystacinus e L. fuscus do Novo Gama. Table 2. First five principal components scores of the size-adjusted morphological variables for L. mystacinus and L. fuscus from Novo Gama, GO, Brazil.

\begin{tabular}{|c|c|c|c|c|c|}
\hline \multirow[t]{2}{*}{ Variáveis } & \multicolumn{5}{|c|}{ Componentes principais } \\
\hline & 1 & 2 & 3 & 4 & 5 \\
\hline Largura do corpo & 0,246 & 0,570 & 0,147 & $-0,108$ & $-0,312$ \\
\hline Altura do corpo & 0,343 & 0,316 & $-0,166$ & $-0,581$ & $-0,351$ \\
\hline Comprimento da cabeça & 0,178 & 0,541 & $-0,160$ & $-0,347$ & 0,042 \\
\hline Largura da cabeça & 0,604 & 0,615 & 0,166 & $-0,085$ & $-0,077$ \\
\hline Altura da cabeça & 0,131 & 0,312 & $-0,716$ & $-0,126$ & $-0,234$ \\
\hline Diâmetro do tímpano & 0,596 & 0,264 & $-0,401$ & 0,291 & $-0,206$ \\
\hline Distância interocular & 0,311 & 0,044 & 0,020 & $-0,212$ & 0,510 \\
\hline Distância olho-narina & 0,296 & $-0,364$ & 0,306 & $-0,161$ & $-0,315$ \\
\hline Diâmetro do olho & 0,295 & $-0,039$ & $-0,491$ & 0,631 & $-0,051$ \\
\hline Distância internasal & 0,770 & $-0,267$ & $-0,138$ & 0,072 & 0,148 \\
\hline Comprimento do braço & 0,562 & $-0,432$ & $-0,313$ & 0,028 & 0,379 \\
\hline Largura do braço & 0,321 & 0,400 & 0,335 & 0,519 & 0,170 \\
\hline Comprimento do antebraço & 0,684 & $-0,205$ & 0,380 & $-0,264$ & 0,168 \\
\hline Largura do antebraço & $-0,165$ & 0,482 & $-0,078$ & 0,640 & 0,188 \\
\hline Comprimento da mão & 0,450 & $-0,076$ & $-0,146$ & $-0,355$ & 0,211 \\
\hline Comprimento da coxa & 0,547 & $-0,453$ & $-0,236$ & 0,072 & $-0,004$ \\
\hline Largura da coxa & 0,002 & 0,520 & 0,497 & $-0,084$ & 0,340 \\
\hline Comprimento da perna & 0,315 & $-0,328$ & 0,628 & 0,200 & $-0,236$ \\
\hline Largura da perna & 0,484 & 0,419 & 0,204 & 0,173 & 0,187 \\
\hline Comprimento do pé & 0,393 & $-0,221$ & 0,328 & 0,334 & $-0,477$ \\
\hline Variância explicada pelos componentes & 3,716 & 2,903 & 2,357 & 2,121 & 1,395 \\
\hline Porcentagem de variância explicada & 18,573 & 14,516 & 11,787 & 10,605 & 6,976 \\
\hline
\end{tabular}

19 Leptodactylus fuscus (13 machos e 6 fêmeas) coletados, apenas sete machos estavam reprodutivos. O comprimento rostro-cloacal (CRC) de Leptodactylus fuscus variou de 42,7 a 51,0 $\mathrm{mm}$ para machos, com o menor individuo reprodutivo tendo $49,2 \mathrm{~mm}$ e para as fêmeas de 45,5 a 52,6 mm.

\section{Discussão}

Fatores climáticos como temperatura e umidade são importantes na vida dos anfíbios e podem limitar sua distribuição geográfica (Owen 1989). Este fator, aliado às características fisiológicas e ecológicas, restringem a distribuição desses animais a locais mais úmidos, necessários à manutenção de sua homeostase e reprodução, refletindo-se assim nos microhabitats selecionados pela espécie (Pough et al.1977). Leptodactylus mystacinus e L. fuscus não diferiram com relação ao período do ano em que foram mais observados. Ambas as espécies foram verificadas nos meses de grande precipitação e com umidade relativa do ar mais elevada e temperatura relativamente alta. Provavelmente esse resultado esteja relacionado a uma grande dependência da água durante os eventos reprodutivos como observado para indivíduos das mesmas espécies, em estudo realizado por Toledo et al. (2003), no Município de Rio Claro.

Embora as duas espécies ocorram no mesmo período do ano, elas diferem com relação aos horários em que são mais observadas (vocalizando ou não). Leptodactylus fuscus em atividade de vocalização foi mais freqüente entre as 19:00 e 21:00 horas, semelhante ao observado por Martins (1988), para a região de Boa Vista, Roraima e L. mystacinus entre 19:30 e 22:30 horas. Diferenças nos horários de maior atividade podem beneficiar as duas espécies de modo que possam utilizar recursos semelhantes, porém em horários mais ou menos distintos reduzindo assim os efeitos negativos que uma espécie teria sobre a outra (Cardoso \& Martins 1987, Ávila \& Fereira 2004, Pombal 1997).

Mesmo sendo diferentes os horários utilizados para os eventos reprodutivos, pelo menos o início da noite foi coincidente entre os dois Leptodactylus estudados. Em espécies que se acasalam na primeira metade da noite, as fêmeas podem ser beneficiadas, pois teriam mais tempo para desovar, minimizando as chances que predadores visualmente orientados teriam de encontrar o casal em amplexo próximo ao nascer do dia, como já sugerido por Pombal (1997) para Physalaemus cuvieri. Provavelmente este fato possa ser estendido às espécies aqui estudadas. Temperaturas mais favoráveis às atividades de vocalização nesse período, podem contribuir também para esse comportamento, assim a segunda metade da noite seria utilizada no forrageamento (Vasconcelos et al. 2003).

Padrões de distribuição espacial diferenciados em anuros podem facilitar a coexistência de várias populações em uma mesma área (Silvano et al. 2003). A ocupação de diferentes microhábitats pode ter evoluído de modo a minimizar as influências de interações como a predação e a competição por recursos e parceiros sexuais entre as espécies integrantes de uma comunidade (Bertoluci \& Rodrigues 2002a, Silvano et al. 2003). As duas espécies de anuros estudadas foram observadas principalmente em áreas abertas e brejosas com predomínio de herbáceas. Ambientes abertos como os encontrados nesse estudo podem constituir um fator limitante na diferenciação dos sítios de vocalização em decorrência da baixa complexidade estrutural desse habitat (Rossa-Feres \& Jim 2001). Feio \& Caramaschi 


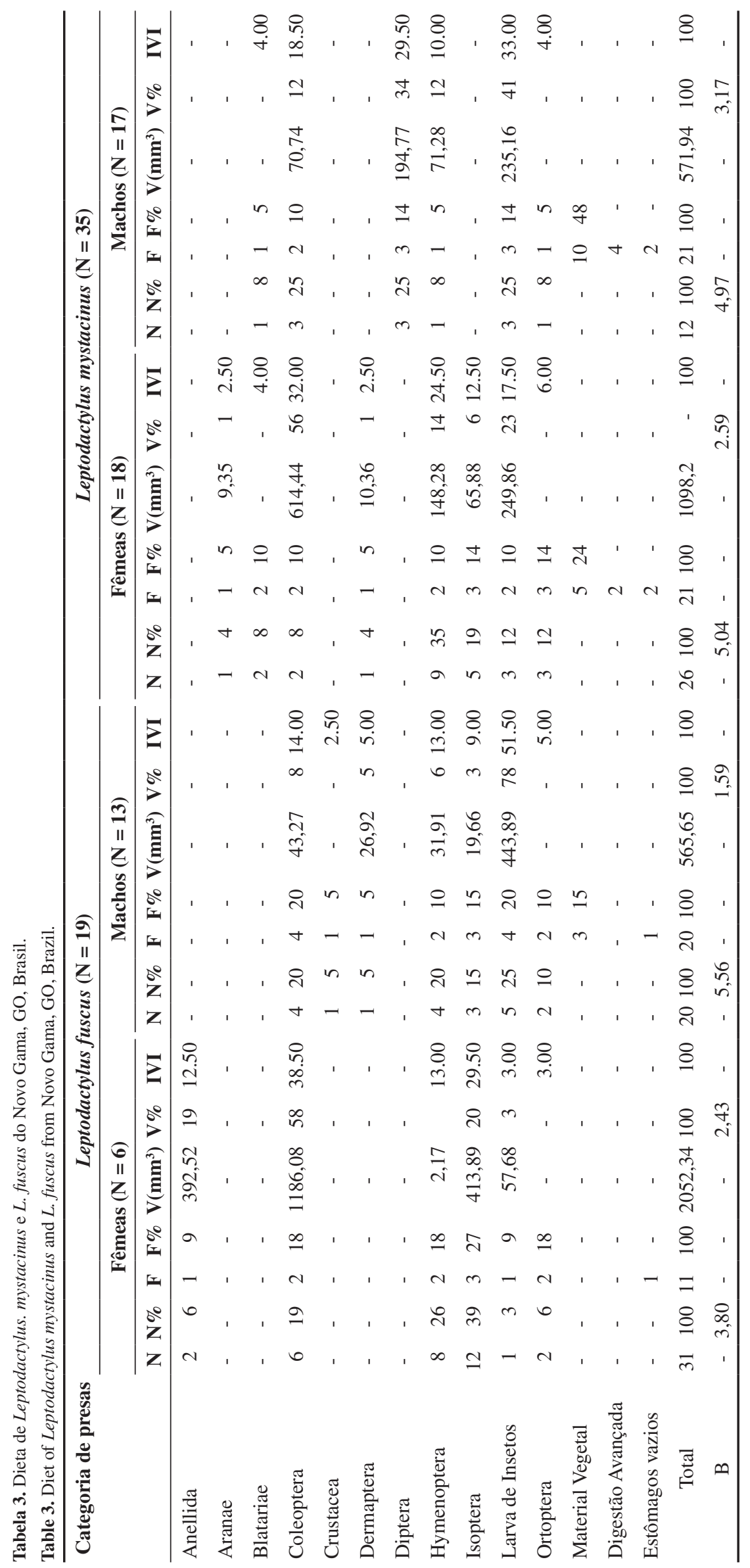


De-Carvalho, C.B. et al.

Tabela 4. Dieta de machos e fêmeas de L. mystacinus e L. fuscus do Novo Gama, GO, Brasil.

Table 4. Diet of male and female L. mystacinus and L. fuscus from Novo Gama, GO, Brazil.

\begin{tabular}{|c|c|c|c|c|c|c|c|c|c|c|c|c|c|c|}
\hline \multirow{2}{*}{ Categoria de Presas } & \multicolumn{7}{|c|}{ Leptodactylus mystacinus $(\mathrm{N}=\mathbf{3 5})$} & \multicolumn{7}{|c|}{ Leptodactylus fuscus ( $\mathrm{N}=19$ ) } \\
\hline & $\mathbf{N}$ & N\% & $\mathbf{F}$ & F\% & $\mathbf{V}\left(\mathbf{m m}^{3}\right)$ & $\mathrm{V} \%$ & IVI & $\mathbf{N}$ & N\% & $\mathbf{F}$ & F\% & $\mathbf{V}\left(\mathbf{m m}^{3}\right)$ & $\mathbf{V \%}$ & IVI \\
\hline Annelida & - & - & - & - & - & - & - & 2 & 4 & 1 & 3 & 392.52 & 15 & 9.50 \\
\hline Aranae & 1 & 3 & 1 & 2 & 9.35 & 1 & 2.00 & - & - & - & - & - & - & - \\
\hline Blattariae & 3 & 8 & 3 & 7 & - & - & 4.00 & - & - & - & - & - & - & - \\
\hline Coleoptera & 5 & 13 & 4 & 9 & 685.18 & 41 & 27.00 & 10 & 20 & 6 & 19 & 1229.35 & 47 & 33.50 \\
\hline Crustacea & - & - & - & - & - & - & - & 1 & 2 & 1 & 3 & - & - & 1.00 \\
\hline Dermaptera & 1 & 3 & 1 & 2 & 10.36 & 1 & 2.00 & 1 & 2 & 1 & 3 & 26.92 & 1 & 1.50 \\
\hline Diptera & 3 & 8 & 3 & 7 & 194.77 & 12 & 10.00 & - & - & - & - & - & - & - \\
\hline Hymenoptera & 10 & 26 & 3 & 7 & 219.56 & 13 & 19.50 & 12 & 24 & 4 & 13 & 34.08 & 1 & 12.50 \\
\hline Isoptera & 5 & 13 & 5 & 11 & 65.88 & 4 & 8.50 & 15 & 29 & 6 & 19 & 433.55 & 17 & 23.00 \\
\hline Larva de Inseto & 6 & 16 & 5 & 11 & 485.01 & 29 & 22.50 & 6 & 12 & 5 & 16 & 501.58 & 19 & 15.50 \\
\hline Orthoptera & 4 & 11 & 4 & 9 & - & - & 5.50 & 4 & 8 & 4 & 13 & - & - & 4.00 \\
\hline Material Vegetal & - & - & 15 & 34 & - & - & - & - & - & 3 & 10 & - & - & - \\
\hline Digestão Avançada & - & - & 6 & - & - & - & - & - & - & - & - & - & - & - \\
\hline Estômagos Vazios & - & - & 4 & - & - & - & - & - & - & 2 & - & - & - & - \\
\hline Total & 38 & 100 & 44 & 100 & 1670.11 & 100 & 100 & 51 & 100 & 31 & 100 & 2617.99 & 100 & 100 \\
\hline B & - & 6.50 & - & - & - & 3.51 & - & - & 4.94 & - & - & - & 3.25 & - \\
\hline
\end{tabular}

Tabela 5. Correlação canônica entre as dimensões das presas e da cabeça de L. mystacinus e L. fuscus do Novo Gama, GO.

Table 5. Canonical correlation between prey and head dimensions of L. mystacinus and L. fuscus from Novo Gama, GO.

\begin{tabular}{|c|c|c|c|c|c|c|}
\hline \multirow[t]{3}{*}{ Medidas da cabeça } & \multicolumn{3}{|c|}{ Leptodactylus mystacinus } & \multicolumn{3}{|c|}{ Leptodactylus fuscus } \\
\hline & \multicolumn{3}{|c|}{ Coeficientes canônicos } & \multicolumn{3}{|c|}{ Coeficientes canônicos } \\
\hline & $\mathbf{1}^{\mathrm{a}}$ variável canônica & $2^{a} v$ & anônica & $1^{\text {a }}$ variável canônica & $2^{\mathrm{a}}$ variá & lônica \\
\hline Comprimento & $-0,41$ & \multicolumn{2}{|c|}{0,22} & 0,19 & \multicolumn{2}{|c|}{$-0,01$} \\
\hline Largura & $-0,11$ & \multicolumn{2}{|c|}{0,88} & $-0,16$ & \multicolumn{2}{|c|}{$-0,97$} \\
\hline Altura & $-0,72$ & \multicolumn{2}{|c|}{0,74} & $-0,99$ & \multicolumn{2}{|c|}{$-0,05$} \\
\hline \multicolumn{7}{|l|}{ Medidas das presas } \\
\hline Maior comprimento & $-0,03$ & \multicolumn{2}{|c|}{0,99} & 0,27 & \multicolumn{2}{|c|}{0,96} \\
\hline Maior largura & 0,75 & \multicolumn{2}{|c|}{0,66} & 0,95 & \multicolumn{2}{|c|}{$-0,31$} \\
\hline Variáveis canônicas & Correlação canônica & $\chi^{2}$ & $\mathbf{P}$ & Correlação canônica & $\chi^{2}$ & $\mathbf{P}$ \\
\hline I & 0,44 & 2,63 & 0,85 & 0,91 & 11,80 & 0,06 \\
\hline II & 0,26 & 0,66 & 0,72 & 0,43 & 1,25 & 0,53 \\
\hline
\end{tabular}

(2002), estudando a herpetofauna do nordeste do Estado de Minas Gerais observaram que L. mystacinus e $L$. fuscus estavam presentes em brejos, áreas alteradas e/ou abertas. Padrão semelhante foi também verificado para essas espécies em outras localidades do país (e.g. Bernarde \& Kokubun 1999, Bertoluci \& Rodrigues 2002b, Borges \& Juliano 2007).

Leptodactylus mystacinus e L. fuscus foram observados próximos a corpos de água lênticos, provavelmente em razão da estabilidade deste tipo de ambiente ou das exigências e vulnerabilidade específica da fase larval. Girinos ficam menos vulneráveis nesses ambientes que dificilmente sofrem alterações como variações abruptas do nível da água e modificação da vegetação marginal (Richards 2002, Eterovick 2003). Leptodactylus mystacinus e L. fuscus utilizaram o solo como principal substrato corroborando com resultados tomados para essas espécies em outras localidades (e.g. Machado et al. 1999, Ávila \& Ferreira 2004, Borges \& Juliano 2007). Provavelmente a presença dessas espécies nesses locais esteja relacionada ao modo reprodutivo adotado, ambas escavam tocas que abrigam seus ninhos de espuma (Ávila \& Ferreira 2004, Haddad \& Prado 2005) que ficam protegidos dos predadores e da dessecação, tendo em vista o efeito do isolamento do ninho (Heyer 1969).

A seleção das presas pode ser influenciada tanto pelo tipo de habitat, quanto pela disponibilidade das mesmas ao longo do ano, podendo variar sazonalmente em termos de quantidade e qualidade. Esses fatores associados à ocupação diferencial do ambiente acabam influenciando nos tipos de presas ingeridas pelos anuros (Van Sluys \& Rocha 1998). As duas espécies em estudos apresentaram dieta baseada principalmente em artrópodes com predominância de certas categorias 
como Isoptera, Hymenoptera, Coleoptera e larvas de insetos havendo certa sobreposição numérica e volumétrica dos itens entre as mesmas. Isso pode ser reflexo da maior disponibilidade destes animais no ambiente durante o período de estudo. Coleoptera, Hymenoptera e larvas de insetos são abundantes no período chuvoso (Pinheiro et al. 2002, Morais \& Diniz 2004) e os Isoptera são bastante diversificados e comuns em áreas de Cerrado (Gontijo \& Junqueira 1991), o que justificaria em parte a predominância desses itens na dieta dos anuros em estudo. Em um trabalho realizado por Duré \& Kehr (2004) com Leptodactylus latinasus e L. bufonius na Argentina, foi verificado que essas espécies seguem cupins por curtas distâncias até a suas colônias, onde poderiam encontrar estas presas em grandes proporções.

Diferenças nas proporções volumétricas das categorias de presas utilizadas pelas duas espécies estudadas podem favorecer a convivência das mesmas na área de estudo. Menin et al. (2005) estudaram espécies sintópicas de hilídeos e observaram que, apesar da grande sobreposição encontrada nas categorias de presas ingeridas, diferenças em outras dimensões, como ocorrência sazonal e volume de presas consumidas podem ser percebidas. Estes autores sugerem ainda que essas diferenças seriam suficientes para permitir a coexistência destas espécies.

Diferenças verificadas na dieta de machos e fêmeas das duas espécies podem refletir necessidades distintas de cada sexo, visto que machos demandam mais energia na vocalização e defesa de território (Woolbright 1982) e já as fêmeas na produção de óvulos contendo as reservas necessárias ao desenvolvimento inicial dos embriões (Gilbert 2005). Comportamento territorialista foi observado para Leptodactylus mystacinus durante as coletas. Ao se realizar um "play-back" próximo a uma toca que abrigava um macho, o mesmo rapidamente se deslocou para sua abertura e começou a "responder" emitindo sons diferentes aos que normalmente são ouvidos para essa espécie. O "play-back” mostrou ser também uma ferramenta eficiente para captura das fêmeas de L. mystacinus, que são facilmente atraídas pelos sons dos machos gravados. Cuidado parental aos ovos, realizados provavelmente por machos em L. mystacinus já foi relatado por Giaretta \& Oliveira-Filho (2006) e pode também ser considerado como uma fonte de consumo de energia.

Outra possibilidade é que em alguns momentos machos e fêmeas podem ocupar lugares distintos como visto para os machos de L. mystacinus que foram encontrados vocalizando algumas vezes dentro de tocas e embaixo de moitas de capim e as fêmeas forrageando sob o solo sem vegetação. Já para $L$. fuscus esse tipo de comportamento não foi visualizado. Os machos vocalizavam próximos às tocas de ovoposição, sobre o solo seco, semelhantes ao encontrado por Martins (1988) em Boa Vista, RR. Esses locais foram também utilizados pelas fêmeas de L. fuscus na área de estudo. Provavelmente a diferença entre os ambientes utilizados influenciaria diretamente nas dietas em cada sexo e espécie. Santos \& Amorim (2006) estudando cuidado parental de $L$. natalensis relatam que as fêmeas eram observadas entre a vegetação, predando invertebrados que se aproximavam dos ninhos ou dos cardumes de girinos. Um comportamento similar foi relatado por Martins (2001), que observou fêmeas de L. podicipinus ingerindo pequenos invertebrados perto de seus ninhos.

A ocorrência de material vegetal nos estômagos dos indivíduos das duas espécies pode ser acidental, ocorrendo em situações em que os artrópodes capturados estavam sobre as plantas (Anderson \& Mathis 1999). Outra hipótese defendida por Santos et al. (2004) é que o material vegetal pode ser ingerido ativamente pelos anuros como auxílio na eliminação de parasitas intestinais e exoesqueleto de invertebrados.

Diferenças no tamanho do corpo foram verificadas para Leptodactylus mystacinus e L. fuscus com as fêmeas sendo maiores que os machos. Essa característica ocorre em cerca de $90 \%$ das espé- cies de anuros e pode estar relacionada com uma maior produção de ovos e fecundidade nas mesmas (Alcântara 1999, Prado \& Uetanabaro 2000, Zug et al. 2001, Alcântara et al. 2007). Os custos relacionados à produção de espermatozóides são relativamente menores, dessa forma um individuo pode ter pequeno porte e mesmo assim produzir uma grande quantidade de gametas. $\mathrm{O}$ tamanho dos machos em espécies de reprodução prolongada, como as deste estudo, pode ser afetado pelos gastos energéticos com a vocalização e diferenças na dieta, contribuindo assim para o menor porte quando comparados às fêmeas (Woolbright 1982).

Mesmo tendo sido poucos os registros de animais vocalizando, é sugerido que Leptodactylus fuscus e Leptodactylus mystacinus se encaixem no padrão de reprodução prolongado proposto por Wells (1977), uma vez que as vocalizações foram ouvidas por dois ou mais meses consecutivos ao longo do ano. Padrão semelhante já foi registrado para essas espécies em estudos realizados em Guararapes, PR por Bernade \& Kokubum (1999) e Rio Claro, SP por Toledo et al. (2003) e por Zina et al. (2007). Os indivíduos foram observados desde o início da estação chuvosa, sendo mais freqüentes durante os meses de outubro e novembro, os quais apresentaram os maiores índices de pluviosidade e temperatura. Esse primeiro fator contribui para uma maior disponibilidade de sítios aquáticos, importantes à reprodução (Aichinger 1987). A maioria dos anfíbios reproduz à noite e apresenta uma sazonalidade reprodutiva que é condicionada, principalmente, pelas chuvas e temperaturas (Cardoso \& Martins 1987, Bertoluci \& Rodrigues 2002b).

Baseado nas informações apresentadas foi possível verificar que os simpátricos L. mystacinus e L. fuscus apresentaram tamanhos diferenciados, sendo a primeira espécie ligeiramente maior que a segunda. Maior porte foi também observado para as fêmeas das duas espécies. Utilizam hábitats e microhábitats semelhantes, com as duas espécies tendo preferência por locais abertos, com predomínio de herbáceas e próximos a corpos d'água lênticos. Não diferem com relação ao período do ano em que são encontradas, sendo mais comuns naquele de maior precipitação e temperatura. Porém apresentam algumas diferenças em relação aos períodos em que são mais observadas (em atividade ou não de vocalização) e às proporções volumétricas em que são utilizadas as categorias de presas. Provavelmente essas sejam as principais diferenças que permitem a coexistência das duas espécies na área. Variações nas proporções numéricas e volumétricas das categorias de presas ingeridas foram também registradas entre os sexos das duas espécies. Estas diferenças estão provavelmente associadas à alocação diferencial de recursos para a produção de gametas ou diferenças ocasionais no uso do espaço pelos dois sexos.

\section{Agradecimentos}

Agradecemos aos senhores Enrique Sevilla e Geraldo Barbosa por terem cedido a área da fazenda Porta do Céu para realização deste trabalho. A todos os colegas que auxiliaram em campo e em laboratório. Aos professores Dr. Daniel Oliveira Mesquita e Dr. Stephen Francis Ferrari e ao amigo Ms. Frederico Gustavo França pelas críticas e revisão do texto. Ao IBAMA pela concessão da licença $\mathrm{n}^{\text {o }}$ 02010.000583/2006-89. As Faculdades Integradas da Terra de Brasília por ter cedido o laboratório e equipamentos necessários à triagem do material.

\section{Referências Bibliográficas}

ALCÂNTARA, M.B. 1999. Ecologia reprodutiva de Scinax centralis (Anura: Hylidae) em uma região do Brasil Central. Dissertação de mestrado, Universidade Federal de Goiás, Goiânia. 
ALCÂNTARA, M.B., LIMA, L.P. \& BASTOS, R.P. 2007. Breeding activity of Scinax centralis (Anura, Hylidae) in Central Brazil. Iheringia, Sér. Zool. 97(4):406-410.

AICHINGER, M. 1987. Annual activity patterns of anurans in a seasonal neotropical environment. Oecologia 71:583-592.

ANDERSON, M.T. \& MARTHIS, A. 1999. Diets of two sympatric Neotropical Salamanders, Bolitoglossa mexicana and B. rufescens, with notes on reproduction for B. rufescens. J. Herpetol. 33(4):601-607.

ÁVILA, R.W. \& FERREIRA, V.L. 2004. Richness of species and density of vocalization of anurans in an urban area of Corumbá, Mato Grosso do Sul, Brazil. Rev. Bras. Zool. 21(4):887-892.

BERNARDE, P.S. \& ANJOS, L. 1999. Distribuição espacial e temporal da anurofauna no Parque Estadual Mata dos Godoy, Londrina, Paraná, Brasil (Amphibia: Anura). Comum. Mus. Cienc. PUCRS, Ser. Zool. 12:127-140.

BERNARDE, P.S. \& KOKUBUM, M.C.N. 1999. Anurofauna do Município de Guararapes, Estado de São Paulo, Brasil (Amphibia: Anura). Acta Biol. Leopoldensia 21(1):89-97.

BERTOLUCI, J. \& RODRIGUES, M.T. 2002a. Utilização de habitats reprodutivos em uma taxocenose de anuros (Amphibia) da Mata Atlântica do sudeste do Brasil. Pap. Avulsos Zool. 42(11):287-197.

BERTOLUCI, J. \& RODRIGUES, M.T. 2002b. Utilização de habitats reprodutivos e micro-habitats de vocalização em uma taxocenose de anuros (Amphibia) da Mata Atlântica do sudeste do Brasil. Pap. Avulsos Zool. 42(11):287-297.

BORGES, F.J.A. \& JULIANO, R.F. 2007. Distribuição espacial e temporal de uma comunidade de anuros do município de Morrinhos, Goiás, Brasil (Amphibia: Anura). Neotrop. Biol. Conserv. 2(1):21-27.

BRASILEIRO, C.A., SAWAYA, R.J., KIEFER, M.C. \& MARTINS, M. 2005. Anfíbios de um fragmento de Cerrado aberto do sudeste do Brasil Biota Neotrop. 5(2): http://www.biotaneotropica.org.br/v5n2/pt/ abstract?article+BN00405022005. (último acesso em 25/06/2008).

CARDOSO, A.J. \& MARTINS, J.E. 1987. Diversidade de anuros durante o turno de vocalizações, em comunidade neotropical. Pap. Avulsos de Zool. 6(23):279-285.

DUELLMAN, W.E., TRUEB, L. 1994. Biology of Amphibians. Ed. Johns Hopkins, New York.

DURÉ, M.I. \& KEHR, A.I. 2004. Influence of microhabitat on the trophic rcology of two Leptodactylids from Northeastern Argentina. Herpetologica. 60(3):295-303.

EITEN, G. 1972. The Cerrado vegetation of Brazil. Bot. Rev. 38(2):201-341.

ETEROVICK, P.C. 2003. Distribution of anuran species among montane streams in south-estern Brazil. J. Trop. Ecol. 19(3):219-228.

ETEROVICK, P.C. \& SAZIMA, I. 2000. Structure of an anuran community in a montane meadow in southeastern Brazil: effects of seasonality, habitat, and predation. Amphibia-Reptilia 21(4):439-461.

ETEROVICK, P.C. \& SAZIMA, I. 2004. Anfíbios da Serra do Cipó. Ed. PUC Minas, Belo Horizonte.

FEIO, R.N., CARAMASCHI, U. 2002. Contribuição ao conhecimento da herpetofauna do nordeste do estado de Minas Gerais, Brasil. Phyllomedusa 1(2):105-111.

FROST, D.R. 2008. Amphibians Species of The Wolrd 5.1 - an online reference. American Museum of Natural History: http://research.amnh. org/herpetology/amphibia/index.php (último acesso em 20/06/2008).

GADSDEN, H.E. \& PALACIOS-ORONA, L.E. 1997. Seasonal Dietary Patterns of the Mexican fringe-toed Lizard (Uma paraphygas). J. Herpetol. 31(1):1-9.

GIARETTA, A.A. \& OLIVEIRA-FILHO, J.C. 2006. Leptodactylus mystacinus (shovel-nosed frog). Parental care. Herpetol. Rev. 37(2):204-205.

GILBERT, S.F. 2005. Developmental Biology. 4 ed. Sinauer Associates Inc. Publishers, Sunderland, Massachusetts.
GONTIJO, T.A. \& JUNQUEIRA, D. 1991 Guild distribuition of some termites from cerrado vegetation in south-east Brasil. J. Trop. Ecol. 7(4):523-529.

HADDAD, C.F.B. \& PRADO, C.P.A. 2005. Reproductive modes in frogs and their unexpected diversity in the Atlantic forest of Brazil. Bioscience 55(3):207-217.

HEYER, W.R. 1969. The adaptive ecology of the species groups of the genus Leptodactylus (Amphibia, Leptodactylidae). Evolution 23(3):421-428.

HEYER, W.R. 1978. Systematics of the fuscus group of the frog genus Leptodactylus (Amphibia, Leptodactylidae). Nat. Hist. Mus. Los. Ang. Cty. Sci. Bull. (29):1-85.

HEYER, M.M., HEYER, W.R., SPEAR, S. \& SÁ, R.O. 2003. Leptodactylus mystacinus. Catalogue of American Amphibians and Reptiles (767):1-11.

MACHADO, R.A., BERNARDE, S.P., MORATO, S.A.A. \& ANJOS, L. 1999. Análise comparada da riqueza de anuros entre duas áreas com diferentes estados de conservação no município de Londrina, Paraná, Brasil (Amphibia: Anura). Rev. Bras. Zool. 16(4):997-1004.

MACHADO, R.A. 2003. Anfíbios da Floresta Atlântica. In Anfíbios da Floresta Atlântica (C.R. Fernandes ed.). Opta Originais Gráficos e Editora Ltda, Curitiba, p.123-149.

MAGNUSSON, W.E., LIMA, P.A., SILVA, W.A. \& ARAÚJO, M.C. 2003. Use of geometric forms to estimate volume of invertebrates in ecological studies of dietary overlap. Copeia 2003(1):13-19.

MARTINS, I.A. 2001. Parental care behaviour in Leptodactyulus podicipinus (Cope, 1982) (Anura, Leptodactylidae). Herpetol. J. 11(1):29-32.

MARTINS, M. 1988. Biologia reprodutiva de Leptodactylus fuscus em Boa Vista, Roraima (Amphibia: Anura). Rev. Bras. Biol. = Braz. J. Biol 48(4):969-977.

MENIN, M., ROSSA-FERES, D.D.C., \& GIARETTA, A. 2005. Resource use and coexistence of two syntopic hylid frogs (Anura: Hylidae) Rev. Bras. Zool. 22(1):61-72.

MORAIS, H.C. \& DINIZ, I.R. 2004. Herbívoros e herbivoria no Cerrado: lagartas como exemplo. In Cerrado Ecologia e Caracterização. (L.M.S Aguiar, A.J.A Camargo. ed.). EMBRAPA, Distrito Federal, p.159-173.

NIMER, E. 1989. Climatologia do Brasil. 2 ed. IBGE, Departamento de Recursos Naturais e Estudos Ambientais, Rio de Janeiro.

OWEN, J.G. 1989. Parttens of herpetofaunal species richness: relacion to temperature, precipition, and variance in elevation. J. Biogeogr. 16(2):141-150.

OYAMAGUCHI, H.M. 2006. Distribuição espacial e temporal de espécies simpátricas de Leptodactylus do grupo fuscus em áreas naturais e antrópicas na região de Itirapina e Brotas, sudoeste do Brasil. Dissertação de mestrado, Universidade de São Paulo, São Paulo.

PIANKA, E.R. 1973. The structure of lizard communities. Ann. Rev. Ecol. Syst. 4:53-74.

PINHEIRO, F., DINIZ, I.R., \& BANDEIRA, M.P.S. 2002. Seasonal pattern of insect abundance in the Brazilian. Austral Ecology 27(2):132-136.

POMBAL, JR. 1997. Distribuição espacial e temporal de anuros (Amphibia) em uma poça permanente na Serra de Paranapiacaba, sudeste do Brasil. Rev. Bras. Biol. = Braz. J. Biol. 57(4):583-594.

POUGH, H.F., STEWART, M.M. \& THOMAS, R.G. 1977. Physiological basis of habitat partitioning in Jamaican Eleutherodactylus. Oecologia 27(4):285-293.

POUGH, F.H., ANDREWS, R.M., CADLE, J.E., CRUMP, M.L., SAVITZKY, A.H. \& WELLS, K.D. 1998. Herpetology. Prentice Hall, Upper Saddle River, New Jersey.

PRADO, C.P.A. \& UETANABARO, M. 2000. Reproductive biology of Lysapsus limellus Cope, 1862 (Anura, Pseudidae) in the Pantanal, Brazil. Zoocriaderos 3(1):25-30.

ROSSA-FERES, D.C. \& JIM, J. 1996. Distribuição espacial em comunidades de girinos na região de Botucatu, São Paulo (Amphibia: Anura). Rev. Bras. Biol. = Braz. J. Biol. 56(2):309-316. 
ROSSA-FERES, D.C. \& JIM, J. 2001. Similaridade do sítio de vocalização em uma comunidades de anfíbios anuros na região noroeste do estado de São Paulo. Brasil. Rev. Bras. Biol. = Braz. J. Biol. 18(2):439-454.

RICHARDS, S.J. 2002. Influence of flow regime on habitat selection by tadpoles in an Australian rainforest stream. J. Zool. Lond. 257(2):273-279.

SANTOS, E.M., ALMEIDA, A.V. \& VASCONCELOS, S. 2004. Feeding habits of six anuran (Amphibia: anura) species in a rainforest fragment in northeaster Brazil. Ilheringa, Ser. Zool. 94(4):433-438.

SANTOS, E.M. \& AMORIM, F.O. 2006. Parental care behaviour in Leptodactylus natalensis (Amphibia, Anura, Leptodactylidae). Iheringia, Série. Zool. 96(4):491-494.

SILVANO, D.L., COLLI, G.R., DIXO, M.B.O., PIMENTA, B.V.S. \& WIEDERHECKER, H.C. 2003. Anfíbios e Répteis. In Fragmentação de Ecossistemas: Causas, efeitos sobre a biodiversidade e recomendações de políticas públicas, (D.M. Rambaldi \& D.A.S. Oliveira, eds.). Ministério do Meio Ambiente/Secretaria de Biodiversidade e Florestas, Brasília, p.183-200.

SIMPSON, E.H. 1949. Measurement of diversity. Nature 163:688. SCHOENER, T.W. 1974. Resource partitioning in ecological communities. Science 185(4145):27-39.

SCHOENER, T.W. 1977. Competition and niche. In Biology of the reptilian. (C. Gans \& D.W. Tinkle, eds.). Academic Press, New York, p.35-136.

STEBBINS, R.C. \& COHEN, N.W. 1997. A Natural History of Amphibians. Princeton University Press, New Jersey.

TOLEDO, L.F. \& HADDAD, C.F.B. 2003. Distribuição espacial e temporal de uma comunidade de anfíbios anuros do município de Rio Claro, São Paulo, Brasil. Holos Environment 3(2):136-149.

THOMÉ, M.T.C. \& BRASILEIRO, C.A. 2007. Dimorfismo sexual, uso do ambiente e abundância sazonal de Elachistocleis cf. ovalis (Anura:
Microhylidae) em um remanescente de Cerrado no Estado de São Paulo, sudeste do Brasil. Biota Neotrop. 7(1): http://www.biotaneotropica.org.br/ v7n1/pt/abstract?article+bn00307012007 (último acesso em 10/07/2008)

VAN-SLUYS, M. \& ROCHA, C.F.D. 1998. Feeding habitats an microhabitats utilization by two syntopic Brazilian Amazonian frogs Hyla minuta and Pseudopaludicula sp. (gr. Falcipes). Rev. Bras. Biol. = Braz. J. Biol. 58(4):559-562.

VASCONCELOS, T.S., ROSSA-FERES, D.C., CANDEIRA, C.P. 2003. Biodiversidade e ambientes de reprodução de anfíbios anuros em Nova Itapirema, região noroeste do Estado de São Paulo. Anais do $6^{\circ}$ Congresso de Ecologia do Brasil. Simpósios: Biodiversidade, Unidades de Conservação, Indicadores Ambientais, Caatinga, Cerrado. São Paulo, p.300-302.

ZINA, J., ENNSER, J., PINHEIRO, S.C.P., HADDAD, C.F.B. \& TOLEDO, L.F. 2007. Taxocenose de anuros de uma mata semidecídua do interior do Estado de São Paulo e comparações com outras taxocenoses do Estado, Brasil. Biota Neotrop. 7(2): http://www.biotaneotropica.org.br/v7n2/pt/ abstract?article+bn00607022007 (último acesso em 25/06/2008).

ZUG, G.R., VITT, L.J. \& CALDWELL, J.P. 2001. Herpetology: an introductory biology of amphibians and reptiles. 2 ed. Academic Press, San Diego.

WELLS, K.D. 1977. The social behavior of anuran amphibians. Anim. Behav. 25(3):666-693.

WOOLBRIGHT, I.I. 1982. Sexual selection and size dimorphism in anuran amphibia. Am. Nat. 121(1):115-199.

Recebido em 16/03/08

Versão reformulada recebida em 21/07/08

Publicado em 08/08/08 